\title{
Combined intestinal and squamous metaplasia of the renal pelvis
}

\author{
R. SALM \\ From the Royal Cornwall Hospital (Treliske), Truro, Cornwall
}

SYNOPSIS A case of combined squamous and intestinal metaplasia of the renal pelvis, associated with hydronephrosis, chronic pyelonephritis, and lithiasis, is reported. The changes are considered to be due primarily to mechanical irritation of the pelvic epithelium.

The epithelium of the urinary passages occasionally undergoes metaplastic changes. This is seen not infrequently in the bladder, but only rarely in the pelvis and ureter. Cystic and glandular transformation of the urinary transitional cell epithelium occurs more frequently than squamous transformation. In a few instances a combination of both squamous and glandular metaplasia has been observed in the renal pelvis, of which the following case is a further example.

\section{CASE REPORT}

W.A.W., a male mental defective aged 55 years, was seen in 1967 with a chronic urinary infection. No history was obtainable, but it was known that he had lost one stone $(6.4 \mathrm{~kg})$ in weight during the past year. His blood pressure was $140 / 90 \mathrm{~mm} \mathrm{Hg}$ and laboratory examinations showed the following results: haemoglobin $89 \%$; WBC 10,300; ESR $27 \mathrm{~mm}$ after one hour; urine culture yielded a growth of coliform bacilli and $B$. proteus. In a straight $x$-ray film of the abdomen a large opacity was present in the right renal area (Fig. 1) and intravenous pyelography showed a hydronephrotic right kidney. Its ability to concentrate dye was somewhat impaired. The function of the left kidney was within normal limits. A diagnosis of rightsided hydronephrosis and lithiasis was made and a right nephrectomy was carried out. Convalescence was uneventful and the patient has remained well and symptomfree after operation.

OPERATION SPECIMEN The kidney was received opened and fixed in formalin. It measured $11 \mathrm{~cm}$ in length and weighed $250 \mathrm{~g}$. Sunken scarred areas were noted on its surface. The cortico-medullary border was obscured, and calyces and pelvis were moderately dilated. In the pelvis there was a central area of irregular outline, measuring about $2.5 \mathrm{~cm}$ in diameter, which was dark red and velvety on palpation. Along its periphery were several greyish areas suggestive of leukoplakia.

Received for publication 12 July 1968.
CALculus This measured $5 \times 4.5 \times 3.5 \mathrm{~cm}$ and weighed $65 \mathrm{~g}$ (Fig. 2). Chemical analysis proved it to consist mainly of calcium oxalate.

MICROSCOPICAL EXAMINATION (67/2319) Sections of the four blocks cut from the renal parenchyma all show the features of a marked chronic pyelonephritis. There is a moderate loss of substance, and below the pelvic lining there are zones of dense infiltration with lymphocytes and plasma cells, occasionally extending downwards to involve the patchily thickened pelvic smooth muscle coat.

The entire central velvety area of the pelvis was cut in 11 blocks. There are many areas of erosion and chronic inflammation. Many of the blocks show extensive areas lined by, often chronically inflamed, mucosa of large bowel type (Fig. 3). Its glands are preponderantly lined by tall, mucin-containing, PAS-positive goblet cells (Fig. 4) displaying well-marked brush borders in trichrome and Papanicolaou stains. Occasional Paneth cells are also demonstrable with numerous eosinophilic cytoplasmic granules in haematoxylin-eosin stains, which prove to be strongly argentaffin in Fontana stains (Fig. 5). A muscularis mucosae is absent, but the pelvic smooth muscle coat is considerably thickened.

The macroscopically greyish areas consist of a thick layer of squamous epithelium with an occasional granular layer and early keratinization (Fig. 6). Glycogen is present within their cytoplasm, but there are no melanocytes or melanophores. Transitions between normal pelvic epithelium and areas of leukoplakia and intestinal metaplasia are demonstrable (Fig. 7), and there is an occasional area of pyelitis cystica.

\section{DISCUSSION}

Squamous and glandular metaplasia of the transitional epithelium of the urinary tract is considered to follow a variety of stimuli. De Navasquez (1950) observed goblet cell transformation of the pelvic epithelium in experimental staphylococcal pyelonephritis, and vitamin A deficiency may lead to leuko- 


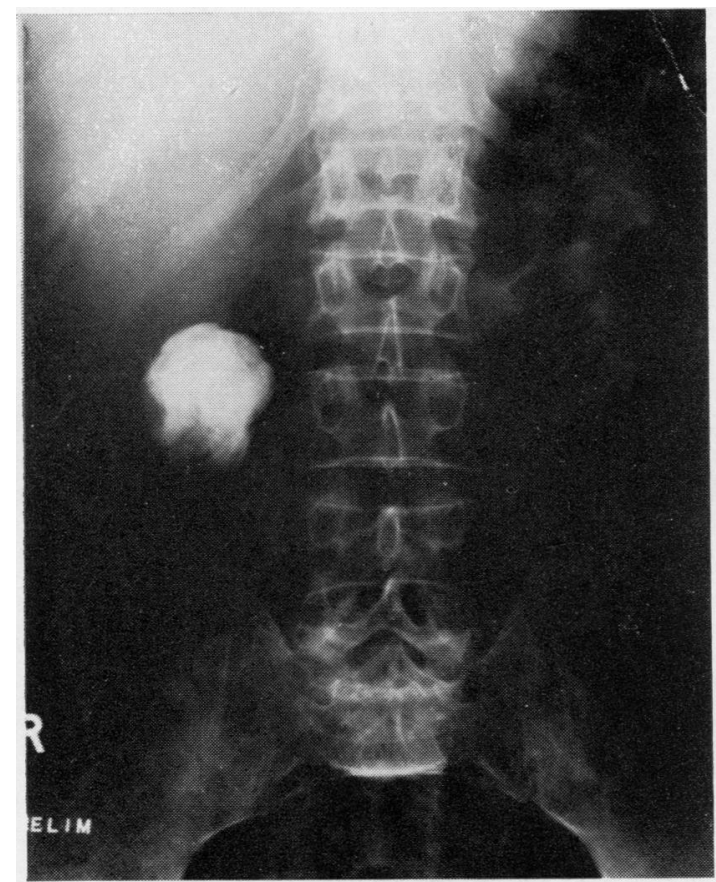

FIG. 1. Straight abdominal radiograph showing large opacity in right renal area.

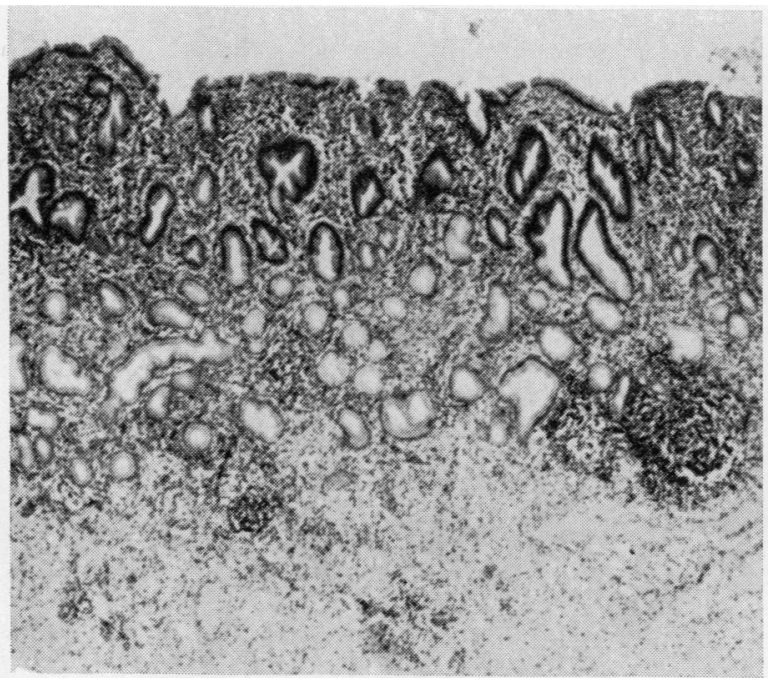

FIG. 3. Intestinal metaplasia of renal pelvis. Absence of muscularis mucosae. Haematoxylin and eosin. $\times 40$.

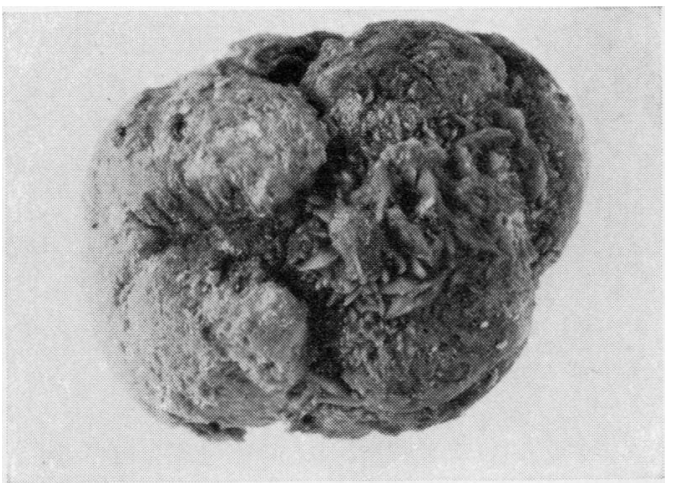

FIG. 2. Renal calculus. Natural size.

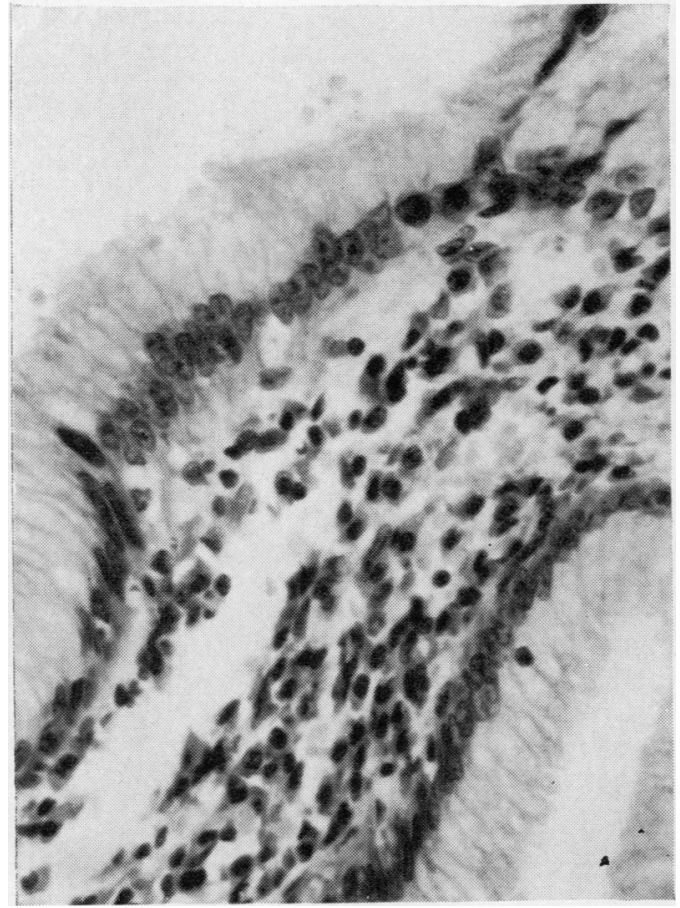

FIG. 4. High-power view of intestinal goblet cells. $\square$ Haematoxylin and eosin. $\times 430$. 


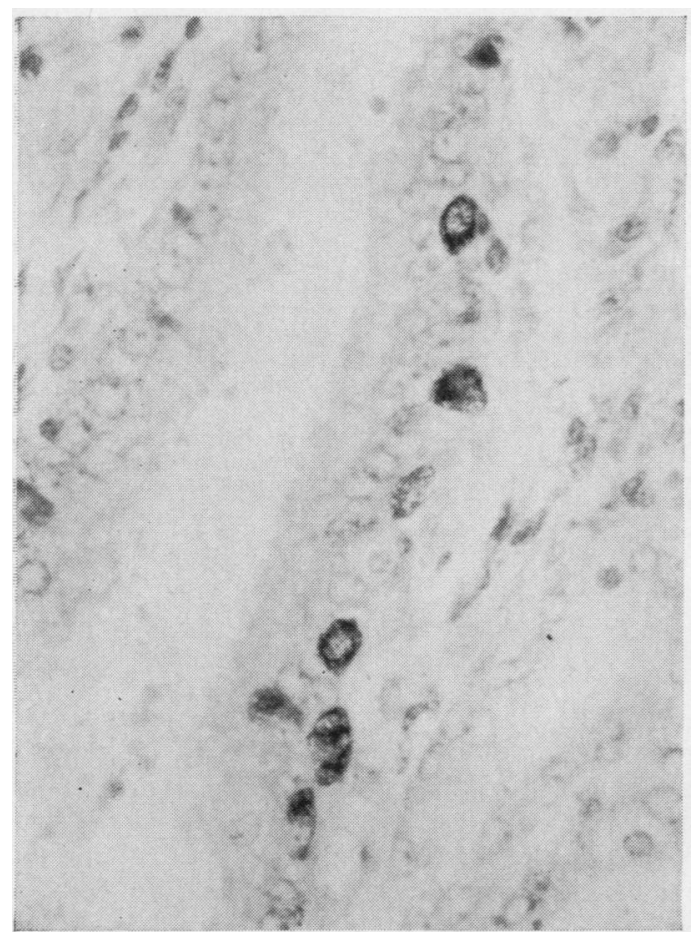

FIG. 5. High-power view of intestinal Paneth cells. Fontana. $\times 430$.

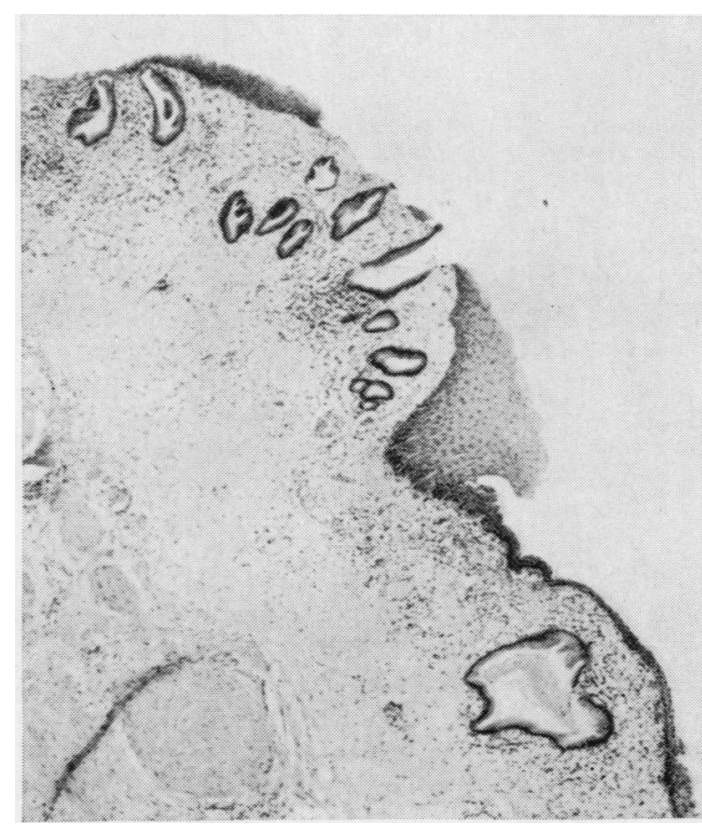

FIG. 7. Area of alternating squamous and glandular metaplasia. Haematoxylin and eosin. $\times 40$.

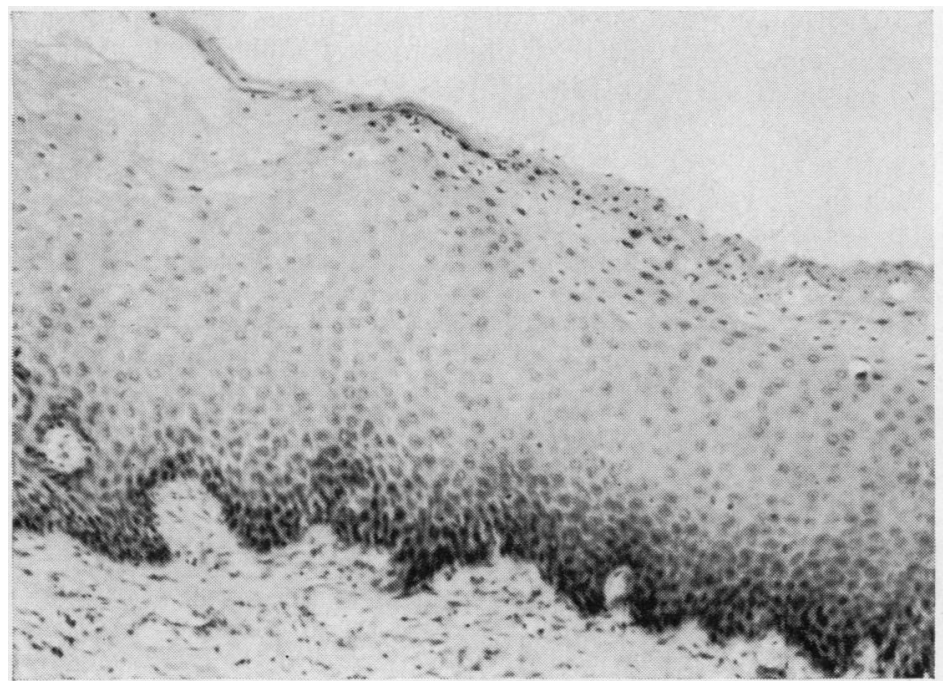

FIG. 6. Area of epidermoid metaplasia. Haematoxylin and eosin. $\times 110$ 
T A B L E

METAPLASIA OF RENAL PELVIS AND URETER WITHOUT ASSOCIATED MALIGNANCY

\begin{tabular}{|c|c|c|c|c|c|c|c|}
\hline Authors and Year & $\operatorname{Sex}$ & Age & Site & Type of Metaplasia & Calculus & Associated Condition & $\begin{array}{l}\text { Smooth } \\
\text { Hypertr }\end{array}$ \\
\hline \multirow[t]{2}{*}{ Paschkis (1912) } & $\mathbf{M}$ & 4 & Ureter & Glandular & - & Pyonephrosis & \\
\hline & $\mathbf{M}$ & 30 & Ureter & Cystic and glandular & Ureteric & - & \\
\hline Brütt (1923) & $\mathbf{F}$ & 24 & Pelvis & Intestinal & - & Pyonephrosis and multiple abscesses & \\
\hline Plaut (1929) & $\mathbf{F}$ & 59 & $\begin{array}{l}\text { Pelvis \& } \\
\text { ureter }\end{array}$ & Intestinal & - & Pyonephrosis & +++ \\
\hline $\begin{array}{l}\text { Foot }(1944) \\
\quad(\text { case } 1)\end{array}$ & $\mathbf{F}$ & 54 & Pelvis & Intestinal & Staghorn & Pyonephrosis & \\
\hline Torassa (1948) & $\mathbf{M}$ & 46 & Pelvis & Intestinal & Staghorn (55 g) & Pyonephrosis and multiple abscesses & \\
\hline $\begin{array}{l}\text { Jacob \& Mau } \\
(1951) \text { (case 1) }\end{array}$ & $\mathbf{M}$ & 36 & Ureter & Intestinal & Ureteric & $\begin{array}{l}\text { Postnephrectomy for renal calculus } \\
\text { and infection }\end{array}$ & \\
\hline $\begin{array}{l}\text { MacLean \& Fowler } \\
\text { (1956) (case 3) }\end{array}$ & $\mathbf{F}$ & 39 & Pelvis & Intestinal & Two calculi & Chronic pyelonephritis & \\
\hline $\begin{array}{l}\text { Krag \& Alcott } \\
\text { (1957) }\end{array}$ & $\mathbf{M}$ & 52 & Pelvis & Intestinal and squamous & $\begin{array}{l}6 \times 3 \mathrm{~cm} \& \text { three } \\
\text { smaller stones }\end{array}$ & Hydronephrosis and pyelonephritis & \\
\hline \multirow[t]{2}{*}{ Gordon (1963) } & $\mathbf{M}$ & 55 & Pelvis & Intestinal and squamous & Recurrent calculi & Chronic pyelonephritis & \\
\hline & $\mathbf{M}$ & 50 & Pelvis & Glandular & & $\begin{array}{l}\text { Bladder dysfunction (spina bifida), } \\
\text { pyonephrosis }\end{array}$ & +++ \\
\hline Towers (1963) & $\mathbf{F}$ & 55 & Pelvis & Cystic and intestinal & & Pyonephrosis & \\
\hline Present case & $\mathbf{M}$ & 55 & Pelvis & Intestinal and squamous & $\begin{array}{l}5 \times 4.5 \times \\
3.5 \mathrm{~cm}, 65 \mathrm{~g}\end{array}$ & Chronic pyelonephritis & $+t$ \\
\hline
\end{tabular}

plakia (Jacob and Mau, 1951). Cystitis, ureteritis, and pyelitis cystica and glandularis are frequently associated with chronic inflammation, and, in the bladder, these lesions may be reversible (Kittredge and Brannan, 1959; Grieve, 1965). In this connexion it is interesting to note that the bladder epithelium in extrophy of the bladder is normal at birth, but that glandular metaplasia almost invariably develops following inflammatory and mechanical irritation (Enderlen, 1904), and that this may progress to adenocarcinoma (Scholl, 1922). Mechanical factors may also be associated with squamous and glandular metaplasia in the renal pelvis and ureter (Table). Of the 13 cases listed all showed evidence of chronic infection, and calculi were present in nine of these, and pyelitis glandularis is occasionally met with in cases of hydronephrosis.

Glandular metaplasia of the urinary tract may resemble the colonic mucosa to such a degree as to suggest a mix-up of specimens, although, as Foot (1944) was the first to point out, there is no muscularis mucosae. Indeed, as a brush border and Paneth cells have now been demonstrated in two out of the three cases examined for their presence (Gordon, case 1, 1963, and in the present case), the occurrence of a true intestinal metaplasia has now been established. (Paneth cells have subsequently been demonstrated in an area of intestinal metaplasia of the bladder reported (Salm, 1967) previously.) Foot (1944) recalled that the bladder and ureters develop from the embryonal cloaca and are thus of endodermal origin. Thus the divergent metaplastic potentialities of the urinary transitional cell epithelium can be readily explained, as squamous metaplasia of stratified epithelium is seen not in- frequently at other sites, and often as a sequel to mechanical irritation, for example, in the oral cavity, bronchi, and cervix.

Suzuki and Milam (1967) reviewed 17 primary mucus-producing adenocarcinomas of the renal pelvis. They found in most cases a longstanding history of chronic inflammation, and calculi were present in all but four cases. Aiken (1955) and Anderson (case 1, 1955) reported cases of squamous cell carcinoma associated with leukoplakia.

In glandular metaplasia gradual transitions from intestinal transformation to adenocarcinoma have been demonstrable in a number of instances (Ackerman, 1946; Ragins and Rolnick, 1950; Anderson, case 2, 1955; Kennedy and Fidler, 1958; Schrodt, Bickers, and Howerton, 1964; Ashley and Hickley, case 1,1964$)$, but in many other cases the neoplasms arose without any preceding metaplastic changes de novo.

A simultaneous occurrence of both squamous and glandular metaplasia has been observed but rarely. In the cases of Ackerman (1946), Aiken (1955), and Schrodt et al (1964) this was associated with malignancy, but in cases unassociated with malignancy $ᄋ$ such divergent metaplasia has been encountered $\mathbb{O}$ only twice previously (Krag and Alcott, 1957; స్ట Gordon, case 1, 1963). In the present case the metaplastic changes must have been principally a sequel 0 to mechanical irritation by the large renal calculus.

The patient had been admitted under the care of $\mathrm{Mr} \mathrm{S}$. 0 R. Adlington to whom I am obliged for the clinical details. Professor R. A. Willis kindly examined the $\mathbb{\mathbb { D }}$ material and read the manuscript. I am very grateful to $\frac{\Omega}{\mathbb{D}}$ Mr W. M. Seymour, chief technician, for his skilful technical and photographic assistance. 
REFERENCES

Ackerman, L. V. (1946). J. Urol., 55, 36.

Aiken, D. (1955). Brit. J. Surg., 42, 412.

Anderson, C. K. (1955). Proc. roy. Soc. Med., 48, 699.

Ashley, D. J. B., and Hickey, B. B. (1964). Brit. J. Urol., 36, 309.

Brütt, H. (1923). Z. Urol. Chir., 14, 157.

Enderlen, E. (1904). Verh. dtsch. path. Ges., 7, 167.

Foot, N. C. (1944). Sth. med. J., 37, 137.

Gordon, A. (1963). J. Path. Bact., 85, 441.

Grieve, J. (1965). Brit. J. Urol., 37, 157.

Jacob, N. H., Jr, and Mau, W. (1951). J. Urol., 65, 20.

Kennedy, J. S., and Fidler, H. K. (1958). Ibid.. 80, 208.
Kittredge, W. E., and Brannan, W. (1959). Ibid., 81, 419.

Krag, D. O., and Alcott, D. L. (1957). Amer. J. clin. Path., 27, 672.

MacLean, J. T., and Fowler, V. B. (1956). J. Urol., 75, 384.

De Navasquez, S. (1950). J. Path. Bact., 62, 429.

Paschkis, R. (1912). Folia Urol., 7, 55.

Plaut, A. (1929). Z. urol. Chir., 26, 562.

Ragins, A. B., and Rolnick, H. C. (1950). J. Urol., 63, 66.

Salm, R. (1967). Brit. J. Urol., 39, 67.

Scholl, A. J. (1922). Ann. Surg., 75, 365.

Schrodt, G. R., Bickers, E., and Howerton, L. (1964). Amer. J. clin. Path., $41,517$.

Suzuki, H., and Milam, D. F. (1967). Arch. Path., 84, 468.

Torassa, G. L. (1948). J. Urol., 60, 393.

Towers, R. P. (1963). J. Irish med. Ass., 53, 179. 